\title{
Expansão e Interiorização da Psicologia: Reorganização dos Saberes e Poderes na Atualidade
}

Expansion and Interiorization of Psychology: Reorganization of Knowledge and Power at Present

Expansión e Interiorización de la Psicología: Reorganización de los Conocimientos y Poderes en la Actualidad

Magda Dimenstein

Universidade

Federal do Rio

Grande do Norte
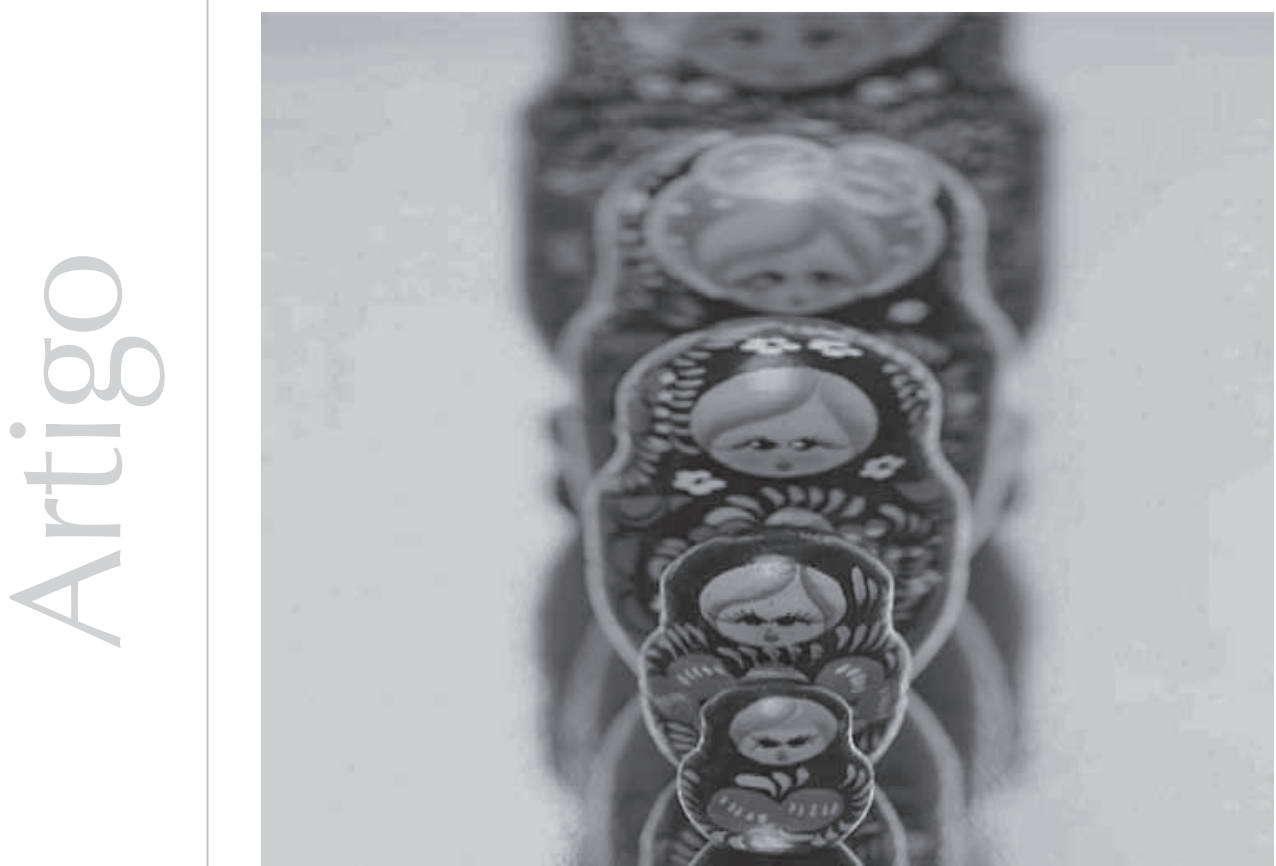
Resumo: Esse artigo objetiva discutir o processo de expansão da categoria dos psicólogos observado nas últimas décadas nas cidades de pequeno e médio porte do País. Esse processo tem apontado uma interiorização da profissão por meio do deslocamento de um contingente expressivo de profissionais e de uma redefinição da Psicologia como área típica dos grandes centros urbanos e capitais nacionais, tal como foi historicamente caracterizada. Pretende-se destacar que tal processo se relaciona com a reestruturação urbana em curso no Brasil, através do novo dinamismo socioespacial das cidades brasileiras devido à reformulação de suas relações financeiras e comunicacionais, da consolidação das políticas de bem-estar social, através da implantação de inúmeros programas, projetos e serviços na área da saúde, saúde mental e assistência social, e da expansão dos cursos de graduação no interior do País, seja através dos programas e demais dispositivos de reforma e expansão das universidades públicas brasileiras, seja através da própria corrida das instituições privadas de ensino superior na busca de novos mercados. Por fim, busca-se problematizar tais movimentos e maquinações da categoria nos jogos de poder na atualidade.

Palavras-chaves: Psicologia. Mudança social. Atitudes profissionais.Política de saúde

\begin{abstract}
This article aims to discuss the process of expansion of the psychologist's category observed on the last decades in small towns and medium-sized cities in Brazil. This process has pointed out an interiorization of the profession by the relocation of an expressive contingent of professionals and a redefinition of psychology as a profession of big cities and national capitals, as it was historically characterized. The article has the objective of showing that this expansion is related to the urban restructuration process in Brazil through the new socio-spacial dynamism in Brazilian cities according to the restructuration of their financial and communicational relations, to the consolidation of the welfare politics, to the implementation of numerous programs, projects and services in health, mental health and social care and to the increase of graduation courses in the countryside, by the reform and expansion of Brazilian public universities programs or by the dispute of private institutions of higher education in search of new markets. Lastly, it tries to discuss the profession's movements and machinations inside the political power at present.
\end{abstract}

Keywords: Psychology. Social change. Ocuppational attitudes. Health care policy.

Resumen: Ese artículo objetiva discutir el proceso de expansión de la categoría de los psicólogos observado en las últimas décadas en las ciudades pequeñas y medianas del País. Ese proceso ha mostrado una interiorización de la profesión a partir del desplazamiento de un contingente expresivo de profesionales y de una nueva definición de la Psicología como área típica de los grandes centros urbanos y capitales nacionales, así como fue históricamente caracterizada. Se pretende mostrar que ese proceso se relaciona con la reestructuración urbana en curso en Brasil, a través del nuevo dinamismo socio espacial de las ciudades brasileñas debido a la reformulación de sus relaciones financieras y de comunicación, de la consolidación de las políticas de bienestar social, a través de la implantación de inúmeros programas, proyectos y servicios en el área de la salud, salud mental y asistencia social, y de la expansión de los cursos de graduación en el interior del País, sea a través de los programas y otros dispositivos de reforma y expansión de las universidades públicas brasileñas, sea a través de la propia corrida de las instituciones particulares de educación superior en la búsqueda de nuevos mercados. Para finalizar, se intenta problematizar los movimientos y maniobras de la categoría en los juegos de poder en la actualidad.

Palabras clave: Psicología. Cambio social. Actitudes profesionales. Politica de salud.

\section{A Psicologia no Brasil, nas duas últimas} décadas, registrou um rápido e versátil processo de expansão para os mais diversos locais, regiões e campos de atuação. Entendemos tal crescimento como decorrente de alguns fatores que buscaremos apresentar ao longo deste texto, dentre os quais destacamos: a) a ampliação do número de psicólogos que atuam no campo do bem-estar social, através de inúmeros programas, projetos e serviços na área da saúde, saúde mental e assistência social, e b) o expressivo número de cursos de Psicologia em funcionamento nos diversos estabelecimentos de ensino superior das mais variadas localidades e regiões do País.

O principal reflexo desse fato tem sido o aumento do contingente de psicólogos que trabalham nas capitais e grandes centros urbanos brasileiros, inclusive de maneira bem mais significativa nas cidades de médio e pequeno porte. É o que podemos constatar na recente pesquisa nacional sobre o psicólogo brasileiro, que registra o quantitativo de 236.100 psicólogos em exercício profissional em todo o País, sendo que, nos últimos 
quatro anos, a proporção de psicólogos no interior (48\%) superou a das capitais (32\%) (Bastos, Gondim, \& Rodrigues, 2010), portanto, um acontecimento que resitua a psicologia brasileira, diferentemente de décadas anteriores, não mais como uma profissão hegemonicamente urbana, como tradicionalmente era conhecida (Rosa, Rosa, \& Xavier, 1988).

Nesse aspecto, propomos apresentar, neste trabalho, um panorama do processo de expansão da Psicologia no Brasil, explicitando três importantes fatores que têm contribuído para sua a interiorização pelos mais recônditos lugares e regiões do País: a) a estruturação de serviços ligados ao campo do bem-estar social, b) o processo de reestruturação, expansão e interiorização da educação superior no nosso país e c) o processo de transição e reestruturação urbana por que passa o Brasil na atualidade. Por fim, pretendemos problematizar tal cenário, os movimentos e maquinações da categoria nos jogos de poder na atualidade indicando seus efeitos na dinâmica social.

\section{A Psicologia e as novas territorialidades da profissão e da formação no Brasil}

Desde a sua regulamentação, em 1962, a partir da Lei no 4.119, a Psicologia tem se apresentado como uma profissão que vem aos poucos conquistando vários espaços de atuação e articulação junto aos mais diversos setores da sociedade brasileira, especialmente junto aos movimentos sociais e à sociedade civil organizada. Dentre as bandeiras de luta levantadas ao longo desses anos de consolidação da Psicologia no Brasil, estão: a) o movimento sanitário e as ações em defesa do SUS e o movimento de luta antimanicomial e de defesa da reforma psiquiátrica, além de outros desdobramentos como a campanha contra o projeto de lei do ato médico, b) a questão dos direitos humanos e da proteção contra a violência e tortura no sistema carcerário/sistema de medidas socioeducativas, a defesa do Estatuto da Criança e do Adolescente - ECA e a questão da redução da maioridade penal, o combate à violência contra o idoso, a mulher e a criança, c) a luta por uma educação para todos e o fortalecimento da educação inclusiva, d) a luta pela democratização das comunicações e demais ações contra a baixaria na TV, e) o debate sobre a violência no trânsito e a questão da mobilidade e f) o debate sobre a questão da terra no Brasil e a elaboração de ações frente a situações de emergências e desastres, dentre outras.

Esses são, portanto, os espaços com os quais a psicologia brasileira passou a se envolver desde a década de 1980, a partir da sua participação nos movimentos de luta social e política e nas ações de afirmação de direitos no País, ou seja, em espaços que viabilizaram tanto a ampliação do espectro de preocupações, debates, responsabilizações e engajamentos em relação aos mais diversos problemas e dificuldades que a população do nosso país enfrenta quanto maior abertura de possibilidades de inserção dos psicólogos no mercado profissional brasileiro.

O maior exemplo disso é a diversidade de lugares e espaços conquistados pela Psicologia na atualidade. De acordo com Vasconcelos (2009), tal avanço só foi possível por causa do "longo e gradual processo de consolidação de uma abertura, pluralização e compromisso social crescente da Psicologia como profissão no Brasil, tendo em vista a ampliação do mercado de trabalho, particularmente no campo das políticas públicas" (p. 11).

As maiores articulações de nossa categoria profissional nos anos 80 foram com o campo da saúde, através do movimento de reforma psiquiátrica e de reforma sanitária, como 
também com grupos de discussão voltados para a proteção da criança e do adolescente e para o movimento sindical. Mas as lutas não pararam por aí. Logo os movimentos sociais, com diversos outros setores da sociedade, começaram a reivindicar, da esfera governamental e legislativa, a regulamentação dos direitos previstos na Constituição recém-aprovada, de modo que, ainda em 1990, foram aprovados o Estatuto da Criança e do Adolescente e a Lei do Sistema Único de Saúde, além da Lei Orgânica da Assistência Social/LOAS, em 1993, o que ampliou significativamente (e de forma mais sistemática) o ingresso de psicólogos no campo das políticas públicas no Brasil (Oliveira, 2005).

Foram as articulações junto aos movimentos sociais e demais setores da sociedade civil organizada, bem como as negociações com o Estado brasileiro, que fortaleceram a presença da Psicologia no campo das políticas públicas, garantindo assim a sustentabilidade da profissão através da ampliação de suas possibilidades de inserção no mercado profissional. Tais investidas valeram à categoria a conquista legal, através de leis, portarias ministeriais, resoluções e decretos federais, da inserção dos psicólogos nas equipes de trabalho dos programas e serviços ligados às políticas públicas no Brasil (Böing, 2009). Isso diversificou, sobremaneira, tanto os domínios clássicos de atuação desse profissional, até então voltados maciçamente para o consultório privado e, em menor número, para a prestação de serviços na esfera da educação e da educação especial e para empresas ligadas à administração pública ou ao setor privado nos mais variados ramos da indústria, do comércio e de serviços; quanto as localidades de atuação dos psicólogos, de forma a não mais restringir a profissão apenas às capitais e aos grandes centros urbanos (Campos, 1983; Rosa, Rosa, \& Xavier, 1988), mas, sobretudo, às cidades de médio e pequeno porte (Bastos, Gondim, \& Rodrigues, 2010), conforme dissemos anteriormente.

Foi esse um movimento, portanto, de duplo reposicionamento da profissão no País, que evitou, assim, o seu colapso em função do crescimento significativo do número de psicólogos a cada ano, o que resultaria, em um futuro próximo, na saturação do seu mercado profissional.

Para termos ideia do grau de oxigenação que o campo das políticas públicas possibilitou à Psicologia no Brasil em termos da abertura do mercado de trabalho para a profissão, apresentaremos alguns dados sobre a diversidade de programas e serviços públicos em que os psicólogos estão se fazendo presente atualmente.

\section{A expansão e a interiorização dos psicólogos nas políticas públicas no Brasil}

Na saúde, de acordo com os registros constantes do Cadastro Nacional de Estabelecimentos de Saúde (CNES), em 2006, contaram-se 14.407 profissionais de Psicologia que atuavam nos serviços de saúde de todo o Brasil (Spink, Bernardes, Santos, \& Gambá, 2007). Tal quantitativo refletia, na época, o percentual de apenas 10,08\% do total de psicólogos registrados no Sistema Conselhos de Psicologia que trabalham diretamente na rede de serviços de saúde que possuem vínculo com o SUS.

Apesar de aparentemente pouco significativo, é importante dizer que, somente no período de 1991 a 1999, “o número de psicólogos trabalhando em instituições públicas de saúde mais que quintuplicou", ou seja, "perdeu em crescimento apenas para os médicos sanitaristas" (Oliveira, 2005, p. 24), sendo que, na época de realização da pesquisa dessa mesma autora, registrávamos o total de 
12.676 psicólogos atuando no SUS (Oliveira, 2005), enquanto hoje verificamos, conforme o Cadastro Nacional de Estabelecimentos de Saúde - CNES, o registro de 33.613 psicólogos atuando no SUS, ou seja, ao longo de cinco anos, quase triplicou o número de psicólogos na rede pública de saúde no Brasil.

O avanço do número de psicólogos nesse campo é fruto da expansão das políticas setoriais bem como das ações, serviços e programas do SUS. A ampliação e o fortalecimento da rede e das ações na atenção básica, através da Estratégia Saúde da Família (ESF), que articula equipes do Programa Saúde da Família (PSF) com o Núcleo de Apoio à Saúde da Família (NASF), além das equipes de Apoio Matricial e das unidades básicas/centros de saúde e unidades mistas, bem como do crescimento das equipes multiprofissionais nos serviços especializados, notadamente nos Centros de Atenção Psicossocial (CAPS), hospitais geral e especializado, e dos serviços de referência em Medicina física e reabilitação e ambulatórios multidisciplinares especializados têm contribuído, sem sombra de dúvida, para o fortalecimento da presença do psicólogo no SUS (Böing, 2009).

Vale ressaltar que, apesar de legalmente o psicólogo ser reconhecido muito mais como um profissional do nível secundário e terciário de atenção à saúde, os gestores desse setor estão mais sensíveis no que diz respeito à presença dos psicólogos na atenção básica e no desenvolvimento de ações de cuidado primário em saúde: vigilância sanitária, clínica ampliada, matriciamento de equipes da saúde da família e ações de promoção e prevenção de agravos à saúde. A atenção básica constitui hoje importante dispositivo que capilariza as ações dos psicólogos nas cidades de médio e pequeno porte do País.

Quanto à assistência social, a reorientação dessa política pública através da implantação do Sistema Único da Assistência Social (SUAS) fez com que os psicólogos se inserissem tanto nos serviços de proteção básica, através dos Centros de Referência de Assistência Social (CRAS), quanto nos de proteção especializada, com os Centros de Referência Especializados da Assistência Social (CREAS).

É difícil precisar o número de psicólogos que atuam na assistência social no Brasil, em função da recentidade da implantação desses dois serviços-chave da Política Nacional de Assistência Social (Brasil, 2004c). Entretanto, através do CadSUAS, sabe-se que atualmente contamos com um total de 5.807 psicólogos atuando em 4.569 unidades de CRAS e 948 unidades de CREAS, número que cobre 4.104 Municípios brasileiros. A meta do Ministério do Desenvolvimento Social (MDS) é estender a cobertura desses serviços para todos os Municípios brasileiros até 2010. Afora isso, registra-se ainda a presença de mais 5.428 psicólogos que também trabalham no campo da assistência social por meio de entidades não governamentais e sem fins lucrativos (associações, fundações, ONGs, etc.) que prestam serviços ao Estado (IBGE, 2006).

Desse modo, a assistência social constitui, ao lado da saúde, um novo e crescente campo de atuação de psicólogos no campo social e nas políticas públicas, conformando assim o fortalecimento da Psicologia no sistema de proteção social brasileiro. Além desses dois espaços, também temos o campo jurídico, que vem registrando forte presença de psicólogos nos diversos Fóruns e Varas de Justiça, na Defensoria Pública e nas delegacias especializadas (mulher, idoso, etc.) bem como no sistema carcerário e no de medidas socioeducativas. Mesmo não tendo levantamentos disponíveis referentes ao número de psicólogos nos diversos setores do Judiciário, reconhecemos a importância desse campo para a expansão da categoria, o que indica maior fortalecimento dos profissionais no que se refere à afirmação de direitos de maneira geral. 
Tal panorama gera indicativos de que o setor das políticas públicas tem se evidenciado na atualidade como um importante campo de engajamento político e de empregabilidade para a profissão (Spink, M. J., Bernardes, J. S., Santos, L., \& Gambá, E. A. C., 2007; Yamamoto, 2007; Bock, 2007; Macedo, Cabral, \& Dimenstein, 2009). As razões para tanto encontram justificativa: 1) no fato da ampla abertura de postos de trabalho para psicólogos nas políticas, programas e projetos sociais no Brasil, em especial na saúde, saúde mental e assistência social, e 2) no próprio fato de que essas políticas têm se explicitado em nosso país como os campos que mais têm contribuído para o processo de interiorização da Psicologia no Brasil, particularmente nas cidades de pequeno e médio porte.

Aprofundando nossos argumentos em relação a esse segundo fator, é importante ressaltar que, desde a aprovação da Lei № 10.216/01 (Brasil, 2004a), que reorienta o modelo da assistência psiquiátrica no Brasil, e com a regulamentação da portaria do MS no 336/02 (Brasil, 2004b), que regulamenta a abertura dos Centros de Atenção Psicossocial para a oferta de cuidados extra-hospitalares e de base territorial no País, foram criados um total de 1.541 CAPS (Brasil, 2010). Destes, a maioria dos serviços ou é do tipo CAPS I, localizados em Municípios de 20.000 a 70.000 habitantes, e concentram $47,04 \%$ do total dos CAPS implantados no País, ou é do tipo CAPS II, localizados em Municípios de 70.000 a 200.000 habitantes, que concentram $26,34 \%$ do total dos CAPS implantados. Portanto, os CAPS hoje são serviços fundamentalmente localizados em cidades de pequeno e médio porte, o que condiciona à saúde mental a função de operar como importante dispositivo de interiorização da Psicologia no Brasil.
Outro dispositivo que tem feito avançar a interiorização da Psicologia em todo o território nacional são os NASF, estratégia recente da Política Nacional de Saúde, implantados através da portaria do MS no 154/08 (Brasil, 2008) para dar suporte ao PSF a partir dos territórios sob a responsabilidade da Estratégia Saúde da Família. De acordo com essa portaria, onde houver equipes de PSF atuando no Brasil, deverá ser implantada ao menos uma equipe NASF, de forma a ampliar as ações de cuidado à populaçãousuária e a fortalecer os princípios da integralidade, intersetorialidade, educação permanente em saúde, promoção da saúde, humanização e controle social. Atualmente, contamos com um total de 1.295 NASF, com a presença de quase 1.000 mil psicólogos atuando nesse programa em todo o País. Vale ressaltar que 90,19\% das equipes NASF estão instaladas nos Municípios do interior do País (Brasil, 2010).

Ao lado das políticas de saúde e saúde mental, a assistência social, através da implantação dos CRAS em todo o território nacional, também tem se colocado como outro importante dispositivo de interiorização do psicólogo, visto que a estruturação da sua rede assistencial de base territorial também segue a lógica dos portes dos Municípios. Desse modo, dados o quantitativo e a especificidade dos Municípios brasileiros e a obrigatoriedade de ter de um a dois profissionais de Psicologia compondo a equipe do CRAS (Brasil, 2006), espera-se que tenhamos, em um futuro bem próximo, o mínimo de 4.892 CRAS em cidades de pequeno porte, de 602 em cidades de médio porte, de 836 em cidades de grande porte, e de 120 CRAS em cidades consideradas metrópoles (acima de 900.000 hab.) (Brasil, 2004a); isso resultará em um total de 6.450 CRAS; em consequência, espera-se um quantitativo de no mínimo 8.000 psicólogos atuando somente no nível básico de proteção 
Vários estudos

(Mello, 1975;

Botomé, 1979;

Campos, 1983;

Conselho Federal

de Psicologia, 1988,

1994; Dimenstein,

1998; Dimenstein

\& Macedo, 2007; Yamamoto,

2007; Bock, 2007)

dão indicativos

de que, apesar

dos discursos

críticos frente à

formação do

psicólogo brasileiro,

convivemos

com uma

permanente ação

reatualizadora do

clássico modelo

individualizante/

privatizante que

deu visibilidade

à Psicologia

como profissão e

que disseminou

profundamente

nossa identidade

e nossa cultura

profissional para

vários estratos da

sociedade brasileira

na atualidade. da assistência social em todo o País, sendo $85,17 \%$ deles localizados em cidades de médio e pequeno porte.

Assim, queremos reforçar a ideia que, diferentemente das duas décadas anteriores, em que tínhamos a predominância do psicólogo brasileiro localizado nos grandes centros econômicos e nas principais cidades do País (Campos, 1983; Rosa et al., 1988), constatamos um reposicionamento da profissão devido ao avanço das políticas públicas através do seu processo de regionalização e municipalização. É o caso da capilarização dos serviços da saúde, saúde mental e assistencial social, a partir da implantação/organização de suas redes territoriais, cuja perspectiva é a de afirmar os princípios da hierarquização, integralidade e intersetorialidade das ações dessas políticas, que têm feito aumentar de forma significativa a presença do psicólogo para os Municípios do interior do País.

Nesse aspecto, pensar sobre esse processo de interiorização e de capilarização da profissão para as mais recônditas regiões do território brasileiro requer de nós, sem dúvida, que acolhamos alguns desafios. O primeiro deles é que a realidade desses Municípios e de suas populações foge do contexto em que o campo de saberes e práticas da Psicologia foram tradicionalmente engendrados, isso porque são Municípios com: a) alto índice de população rural (44,93\%), cuja atividade produtiva é centrada no extrativismo ou nas atividades agrícola, pecuarista e do pescado para a comercialização local desses produtos, b) frágil dinamismo econômico por causa dos níveis incipientes de desempenho institucional, o que leva à precarização das condições de vida da população e à completa dependência dessas localidades em relação ao governo federal, c) situação de rivalidade política local e as corriqueiras práticas de centralismo, autoritarismo, clientelismo e descompromisso social de certos gestores frente às necessidades da população, e d) o fato de essas localidades contarem com uma significativa parcela da população que vive com renda per capita abaixo da linha de indigência $(27,39)$ ou de pobreza $(49,86 \%)$, com $6,87 \%$ de suas crianças de 7 a 14 anos fora da escola, 9,09\% das mulheres de 15 a 17 anos com filhos, 6,55\% da população em idade de 65 anos ou mais, e com 14,48\% da população sendo portadora de algum tipo de deficiência (Brasil, 2004c).

O segundo desafio é que é urgente a tarefa de fortalecermos nossos modos de atuar e de formar profissionais, a fim de fazer avançar o clássico modo de trabalho em Psicologia que emergiu fortemente na década de 70, e que se aprofundou nos anos 90 com a efetivação do receituário neoliberal implantado no País. Vários estudos (Mello, 1975; Botomé, 1979; Campos, 1983; Conselho Federal de Psicologia, 1988, 1994; Dimenstein, 1998; Dimenstein \& Macedo, 2007; Yamamoto, 2007; Bock, 2007) dão indicativos de que, apesar dos discursos críticos frente à formação do psicólogo brasileiro, convivemos com uma permanente ação reatualizadora do clássico modelo individualizante/privatizante que deu visibilidade à Psicologia como profissão e que disseminou profundamente nossa identidade e nossa cultura profissional para vários estratos da sociedade brasileira na atualidade.

O terceiro desafio diz de uma operação mais complexa, mas que está intimamente conectado com os anteriores. Michel Foucault (2008), em seu debate sobre o biopoder, regime político que trata a vida como objeto, afirma que tanto a vida (em sua dimensão individual e coletiva) como a subjetividade tornaram-se campos de investimento de relações de força e poderes. A finalidade para tanto reside na articulação de ações que façam organizar e controlar as pessoas nos espaços em que vivem e por onde circulam, registrando e classificando certas condutas, a fim de modelar e fabricar suas vidas a partir do seu cotidiano. 
No que se refere ao campo social, dependendo da forma como atuamos, tal dimensão do biopoder pode ser acionada a partir de um território bastante profícuo de investimento de práticas governamentais especialmente voltadas para famílias e grupos populacionais margeados de direitos. É o que podemos constatar, por exemplo, a partir de certos modelos de práticas desenvolvidos nos programas/serviços da saúde (PSF/ NASF), saúde mental (CAPS) e assistência social (PAIF/CRAS), quando balizam suas ações de intervenção através de mecanismos de regulação e controle das populações através dos indivíduos e suas famílias, ou seja, por ações de gestão e governo de condutas e subjetividades de que falávamos anteriormente, com o objetivo de basear ou redimensionar tais vidas segundo a ordem social vigente.

É nesse sentido que entendemos ser importante ampliar a discussão sobre o processo de expansão e interiorização do psicólogo brasileiro para colocarmos na ordem do dia o debate sobre possíveis manobras de "supervalorização de nossa (clássica) cultura profissional", ao mesmo tempo em que se tem "construído a ideia de que a atividade do psicólogo é essencial à sociedade" (Dimenstein, 1998, p. 70). Precisamos inclusive pensar com maior preocupação sobre certas estratégias da psicologia de aproximação dos movimentos sociais e suas bandeiras de luta, não só como forma de ampliar o campo de problematização e intervenção da profissão mas também de garantir certa suficiência a essa categoria nos momentos de crise.

Afinal, o debate em torno da questão social e do compromisso do psicólogo não ganhou ares de manobra, para conectar ações e interesses da categoria às redes de saberpoder hegemônicas (a partir da aproximação entre nossa cultura profissional e o ideário neoliberal) como forma de irmos cada vez mais a lugares onde anteriormente não existíamos? Não estaríamos aí a acionar dispositivos de ação biopolítica, operando o controle dos corpos e da vida? Enfim, essa expansão e interiorização da profissão estão a serviço de quê? De quem? De romper com um certo programa normativo/normalizador de condutas que é definidor de nossas ações profissionais e da forma como nos constituímos psicólogos, ou de deflagrar na (e a partir) da profissão discursos/intervenções capazes de criar possibilidades e espaços para a produção de alteridades e de afirmação de direitos?

\section{A expansão e a interiorização da formação dos psicólogos no Brasil}

Outro importante estrato dessa discussão, que também tem reforçado essa tendência quanto à interiorização da Psicologia para as cidades de médio e pequeno porte no Brasil, é a abertura de novos cursos de formação de psicólogos nas regiões mais periféricas do território nacional, em vez de somente nos grandes centros urbanos e demais capitais do País. Esse movimento tem sido reforçado pela instalação de instituições de ensino superior (IES) públicas e privadas em cidades consideradas polo de desenvolvimento regional ou nas demais áreas estratégicas da dinâmica produtiva, comercial e do setor de serviços do País.

Para melhor debater esse tema, apresentaremos mais detidamente alguns dados sobre a educação superior no Brasil, e, em seguida, situaremos o processo de interiorização do ensino da Psicologia pelo País, que, em nossa opinião, constitui importante vetor do processo de expansão e redefinição da Psicologia como profissão típica dos grandes centros urbanos e capitais nacionais. 
1 Programa de Apoio a Planos de Reestruturação e Expansão das Universidades Federais, criado em 2006, que, com o Programa Universidade para Todos - PROUNI, objetiva ampliar o número de vagas na educação superior em, pelo menos, mais $30 \%$ dos jovens de 18 a 24 anos até 2010 (Brasil, 2007).
Os dados do INEP de 2007 registram que há no Brasil 2.281 instituições atuando no setor. Quanto à natureza administrativa dessas IES, 248 são públicas $(10,9 \%)$ e 2.032, privadas $(89,1 \%)$, organizadas em 183 universidades (8\%) e 2.098 estabelecimentos, que podem ser agrupados como institutos superiores, centros universitários e faculdades isoladas (92\%). Em relação aos locais de funcionamento, 825 do total das IES do País têm seu funcionamento nas capitais $(36,16 \%)$ e 1.456 nas cidades do interior (63,84\%). Além disso, dos 23.488 cursos de graduação ofertados por essas instituições em todo o País, 8.159 deles realizam-se nas capitais $(34,73 \%)$ e 15.329 nas cidades do interior $(65,26 \%)$, que dispõem de um total de 4.880.381 alunos matriculados em todo o território nacional, distribuídos de forma que 2.211.982 deles estudam nas capitais $(45,32 \%)$ e 2.668 .399 nas cidades do interior (54,67\%) (Brasil, 2009).

Esses dados denotam uma supremacia do âmbito privado em detrimento do público em relação à educação superior no Brasil e uma alta quantidade de instituições que priorizam apenas as ações de ensino, parâmetro esse que acaba por subverter a concepção da educação superior fundamentada pela articulação entre o ensino, pesquisa e extensão, já que, na prática, o sistema de educação superior brasileiro expandiu-se com a proliferação de estabelecimentos privados isolados, transformando a clientela desse setor em meros consumidores educacionais (Martins, 2009).

Além disso, a forma pela qual vem se configurando a expansão do ensino superior no País, com o elevado quantitativo de IES e cursos no interior, especialmente privados, demonstra que pouco avançamos em relação à democratização do setor. A justificativa para tanto é a pouca diferença na proporção entre o número de matriculados na capital e no interior, o que torna o acesso ao ensino superior ainda restrito para a maioria dos brasileiros.

Sobre o atual quadro de expansão da educação superior, Vargas (2007) e Martins (2009) o analisam como fator resultante de uma política nacional bem mais arrojada do que aquelas efetivadas a partir da reforma universitária de 1968. Para esses autores, somente no período FHC foi notório o processo de expansão e interiorização desse setor por meio de sua privatização. $\mathrm{O}$ argumento daqueles autores encontra justificativas: a) no salto exponencial no número de matrículas ocorrido entre 1995 e 2002 no setor privado, que passou de 1,7 milhões para 3,5 milhões de estudantes (ou seja, um crescimento de $209 \%$,), e b) no alto índice de crescimento do número de IES privadas no período de 1994-2002, com especial atenção para o salto de 63 para 84 universidades privadas nesse mesmo período, para o fato de que, dos 77 centros universitários criados nesse período, 74 deles eram privados, e para o fato de que somente no ano 2002 se atingiu o pico de criação de 234 novas instituições privadas de ensino superior no País. Verifica-se, portanto, clara supremacia do setor privado em detrimento do público, já que o número de universidades públicas no período $\mathrm{FHC}$ ficou praticamente estagnado em função do marco legal e jurídico implementado pelo receituário neoliberal em vigência no País (Vargas, 2007; Martins, 2009).

Em relação ao governo Lula, o argumento dos mesmos autores é que, apesar de termos caminhado mais recentemente para o aumento do número de vagas e de titulações nas instituições federais de ensino superior (IFES), através do REUNI ${ }^{1}$ - política tanto de expansão quanto de interiorização da educação superior pública no Brasil, seja com a criação de novos campi nas IFES já existentes (até o momento, foram criados 
48 novos campi), seja com a criação de novas IFES (até o momento, foram criadas 10 novas universidades em todo o território nacional) (Brasil, 2007) -, também tivemos um intenso fortalecimento do setor privado de ensino superior, através a) do expressivo aumento de IES privadas em todo o País, b) da implementação do PROUNI, que prevê a concessão de bolsas de estudo integrais e parciais em IES privadas, c) do acelerado processo de aquisições e incorporações de IES isoladas e mesmo de redes universitárias por grandes empresas do ensino superior (internacionalização do setor privado de educação superior) e d) das dificuldades enfrentadas nas ações de regulação e controle desse setor (Vargas, 2007; Sguissard, 2008; Martins, 2009).

Tais fatos, ao longo do governo $\mathrm{FHC}$ e, especialmente, do governo Lula, têm requisitado e contribuído para a ampliação e a interiorização da educação superior privada no País. Esse processo tem se constituído a partir da privatização direta do setor, especialmente em regióes consideradas polo e subcentros regionais de desenvolvimento, e também colabora com a chamada privatização indireta, através do fortalecimento das relações entre o setor privado e público e a viabilização de ações de mercatilização do conhecimento (Mancebo, 2007), como por exemplo:

a) formulação de contratos de pesquisa com empresas, venda de serviços e consultoria por meio de parcerias estratégicas entre universidades, institutos tecnológicos e empresas, b) estímulo à participação de instituições produtoras de conhecimento, através da transferência de tecnologia das universidades e dos centros de pesquisa para inovação das empresas (incubação de empresas no espaço público), c) compartilhamento de infraestrutura, equipamentos e recursos humanos para a produção de tecnologia para inovação das empresas e auxílio financeiro extra para instituições de pesquisa (participação dos lucros) que prestem serviços (transferência de tecnologia) para empresas (Mancebo, 2004, pp. 555-556).

Sobre o atual quadro de interiorização da educação superior no País, Duarte (2008) acredita que estejamos em meio a um processo de pulverização regional do setor, que só tende a se intensificar nos próximos anos devido ao interesse de investidores em regiões ainda pouco exploradas e a promessa do REUNI, do governo federal. É o que podemos constatar, por exemplo, com a queda da representatividade da Região Sudeste, que monopolizava, em 1997, $61,44 \%$ do total de IES no Brasil, e, em 2006, esse índice caiu para 48,1\%, apesar do crescimento de $97,64 \%$ novas IES nesse mesmo período. Em contrapartida, a Região Nordeste foi a que mais cresceu no período, com aumento de $307,92 \%$ no número de IES, além do crescimento de $297,05 \%$ da Região Norte, seguido de 222,5\% da Região Sul e de $164,13 \%$ da Região Centro-Oeste.

Para a autora, as razões dos altos índices de crescimento das regiões Nordeste, Norte e Centro-Oeste brasileiro encontram justificativas: 1) na alta demanda pela educação superior nessas Regióes, especialmente nas localidades mais interioranas dos seus Estados, 2) no valor das matrículas e mensalidades mais acessíveis ao perfil socioeconômico da região, 3) na elevação do rendimento domiciliar do morador dessas Regiões, especialmente nos Estados do Nordeste brasileiro, 4) no aumento do Índice de Desenvolvimento Social em todo o País, especialmente com relação à queda da desigualdade social entre o Nordeste e o Sudeste, que era de 4,5 vezes em 1996 e passou para 2,4 vezes em 2006; 5) em consequência, houve maior número 
de investimentos com a instalação de grandes indústrias e com a formação de polos e áreas de negócios, produção e serviços nos Estados dessas Regiões (Duarte, 2008).

Especificamente sobre as graduações em Psicologia no Brasil, contamos com 424 cursos/ habilitações que ofertam 65.508 vagas/ano nos seus processos seletivos. Esses cursos mantêm 110.609 alunos matriculados, dos quais 94.441 (85,38\%) estudam em instituições privadas, e apenas 16.168 (14,61\%) nas públicas, do tipo federal, estadual e municipal. Além disso, 46,7\% dos cursos e 58,72\% das vagas de Psicologia ofertadas no País estão concentradas na Região Sul/ Sudeste, conforme demonstra a Tabela 1.

Tabela 1. Número de cursos e vagas de Psicologia por região geográfica

\begin{tabular}{lll}
\hline & Cursos & Vagas/ano \\
\hline Norte & 29 & 3.481 \\
Nordeste & 67 & 9.228 \\
Centro-Oeste & 32 & 4.567 \\
Sudeste & 198 & 38.471 \\
Sul & 98 & 9.761 \\
Total & 424 & 65.508 \\
\hline Fonte dos dados: INEP/MEC em fev/2009
\end{tabular}

Fonte dos dados: INEP/MEC, em fev./2009

São dados que corroboram os indicadores nacionais anteriormente referidos, bem como convergem com os dados relatados nos estudos de Lisboa e Gonçalves (2009) e Yamamoto, Souza, Silva e Zanelli (2010), especialmente em termos da hegemonia do número de estabelecimentos e de vagas do ensino superior privado em detrimento do público e da concentração do número de curso/vagas na Região Sul/Sudeste, apesar do crescimento das demais Regiões, em especial dos Estados do Nordeste brasileiro.

Além disso, são dados que também mantêm a Psicologia como uma área cuja formação acontece prioritariamente em IES privadas, tendo em vista o histórico dessa formação no País (Gomide, 1988) e o aprofundamento do processo de mercantilização vigente no setor, contexto que, se não alterado o modo como somos formados e nos constituímos psicólogos, só reforça o "território que compartilha da 'cultura psicológica' a partir da consolidação de um 'ethos' individualista e 'intimista', no qual os especialistas 'psi' são um efeito e mais um dispositivo difusor, com um grande potencial de intervenção no espaço social" (Mancebo, 1997, p. 20). 


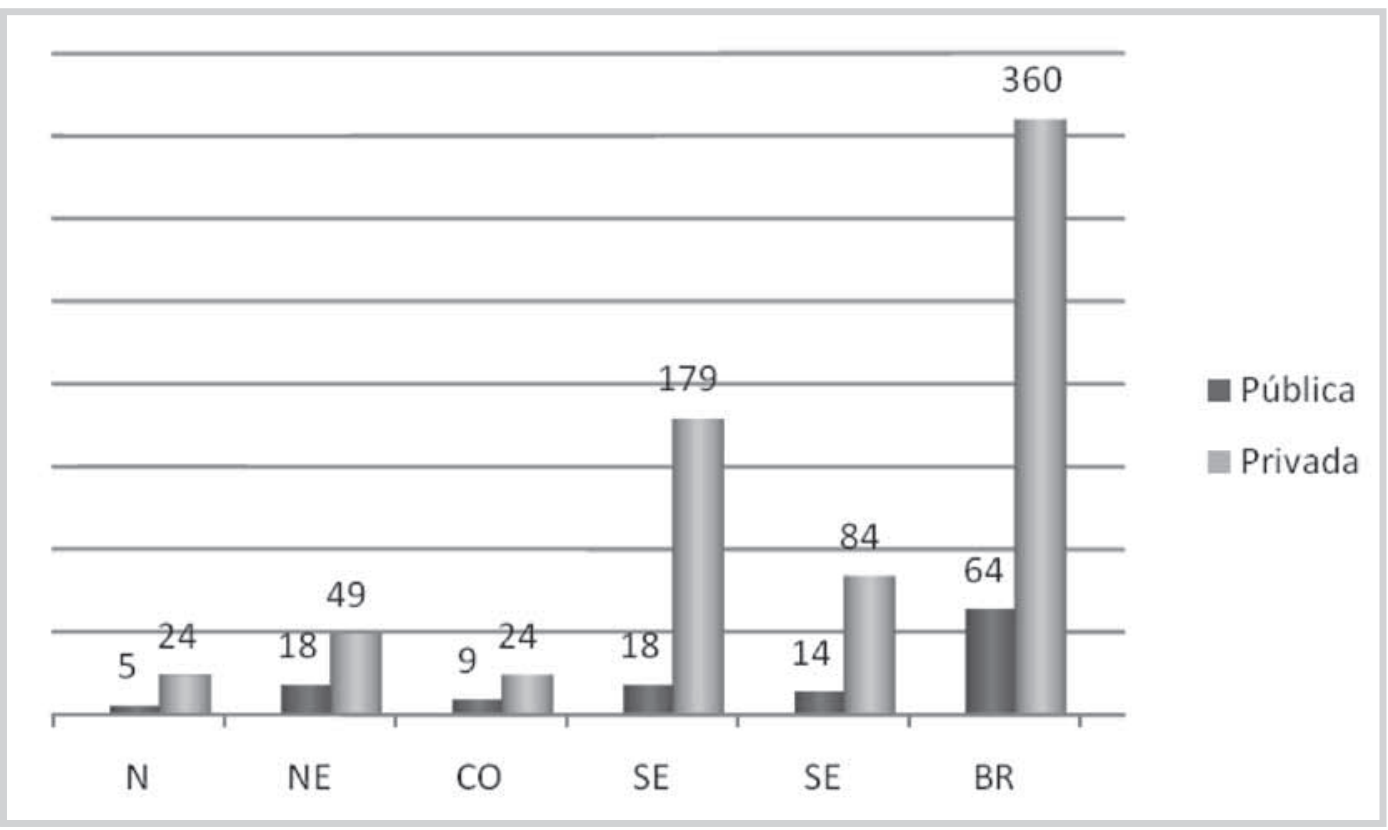

Fonte dos dados: INEP/MEC, em fev./2009

Figura 1. Comparativo dos cursos de Psicologia em estabelecimentos públicos e privados de ensino por região geográfica

De acordo com a Figura 1, na média nacional, registram-se entre os cursos de Psicologia o funcionamento de 360 IES privadas contra apenas 64 públicas, ou seja, a cada 10 IES que oferecem o curso de Psicologia no País, 8 são privadas. Essa relação se acentua ainda mais nos Estados das Regiões Sul/Sudeste, seguida, em menor frequência, pelas outras Regiões do País, dado que evidencia o curso de Psicologia como cada vez mais atrativo para as IES privadas, visto possuir a) fácil organização e aparelhamento, pois, muitas vezes, conta com um quadro de docentes pouco qualificados, bibliotecas com número reduzido de livros e alguns poucos laboratórios e b) apresentar grande demanda de pessoas interessadas em cursá-lo, tendo em vista o lugar social que a Psicologia alcançou no País com sua cultura profissional, como "perscrutadores das intimidades" e agentes de recondução (ou remapeamento de subjetividades) de indivíduos, famílias e grupos sociais, na busca da felicidade possível e de território seguro frente às intempéries e aos conflitos da vida contemporânea (Mancebo, 1997), além da plasticidade que tem a Psicologia de se inserir nas mais diversas áreas ou campos de atividade a partir do exercício liberal da profissão (consultorias, prestação de serviços ou atividade autônoma) e, mais recentemente, da ampliação e interiorização do seu mercado profissional através das políticas públicas.

Tabela 2. Cursos de Psicologia criados no Brasil entre as décadas de 1950 e 2000

\begin{tabular}{lcclllll}
\hline & Anos 50 & Anos 60 & Anos70 & Anos 80 & Anos 90 & Anos 2000 \\
\hline Norte & - & - & 1 & 2 & 3 & 23 & \\
Nordeste & - & 3 & 8 & 2 & 13 & 43 & \\
Centro-Oeste & - & 2 & 3 & 1 & 1 & 22 & \\
Sudeste & 3 & 9 & 30 & 9 & 40 & 112 & \\
Sul & - & 2 & 12 & 4 & 21 & 60 & \\
Total & 3 & 16 & 54 & 18 & 78 & 260 & \\
\hline
\end{tabular}

Fonte dos dados: INEP/MEC, em fev./2009 
Em relação ao crescimento do número dos cursos de Psicologia no País (Tabela 2), seguiu-se a mesma lógica do processo de expansão do ensino superior. Os primeiros cursos surgiram ainda na década de 50, na PUC-RJ, no ano 1953, seguido pelo da USP, em 1958. Nas décadas de 60 e 70, ocorreu verdadeira explosão de cursos de Psicologia por todo o País, fruto do processo de expansão do ensino superior brasileiro, especialmente do setor privado, em decorrência da reforma universitária de 1968. Somente nesse período dos anos 60/70, foram abertos 70 novos cursos, sendo que $70 \%$ deles funcionava no setor privado (Gomide, 1988).

Na década de 1980, ocorreu uma desaceleração no processo de expansão do ensino superior em função da crise econômica, expressa em um grave quadro inflacionário e no aumento das taxas de desemprego no País. Data desse período o surgimento de várias críticas sobre a qualidade do ensino privado por parte de várias associações profissionais e de outros segmentos da sociedade civil, e, diante desse descontentamento, o governo federal acabou por suspender temporariamente a criação de novos cursos nos estabelecimentos já existentes (Sousa, 2006; Sobral, 2000), o que fez diminuir sobremaneira o número de abertura de cursos de Psicologia nesse período, pois apenas 18 tiveram autorização.

A partir de meados dos anos 90, o setor voltou a crescer fortemente devido aos estímulos governamentais do governo $\mathrm{FHC}$, de que falamos anteriormente, bem como do governo Lula, a partir dos anos 2000, que, cada um a seu modo, intensificaram o processo de escalada da privatização do ensino superior no Brasil, seja direta, seja indiretamente.
Na Tabela 2, podemos acompanhar os saltos de crescimento dos cursos de Psicologia no período dos anos 90, momento em que foram criados 78 novos cursos, e nos anos 2000, quando foram criados 260 novos cursos. Tal crescimento se deveu aos fortes estímulos governamentais trazidos pela nova política adotada pelo Conselho Nacional de Educação ainda em 1990, com a flexibilização diante dos processos de autorização, reconhecimento e credenciamento de cursos de instituições particulares, ação que encontrou justificativa na incorporação de determinados princípios das agendas de organismos internacionais, que recomendavam a desregulamentação do ensino superior e a retração de gastos governamentais para esse nível de ensino, cuja maior consequência foi o fortalecimento e a ampliação do setor privado em detrimento da estagnação do setor público (Martins, 2009).

Além disso, no final dos anos 90 e início dos anos 2000, a alta demanda pela educação superior em outras regiões do País, como em polos regionais de desenvolvimento no Sul e no Sudeste e em subáreas de desenvolvimento nos Estados do Nordeste e do Centro-Oeste, fizeram com que algumas IES privadas acompanhassem os investimentos do setor industrial, das áreas de negócios e/ou de produção e serviços pelo interior do Brasil, para efetivar assim novos domínios no mercado educacional. O objetivo foi ampliar a busca por regiões promissoras de investimento para o setor e deixar aquelas consideradas já saturadas, como alguns mercados das grandes capitais e regiões metropolitanas (Neves, Raizer, \& Fachinetto, 2007).

Através da Figura 2, podemos acompanhar o número de cursos de Psicologia localizados nas capitais e nas cidades do interior dos Estados brasileiros. 


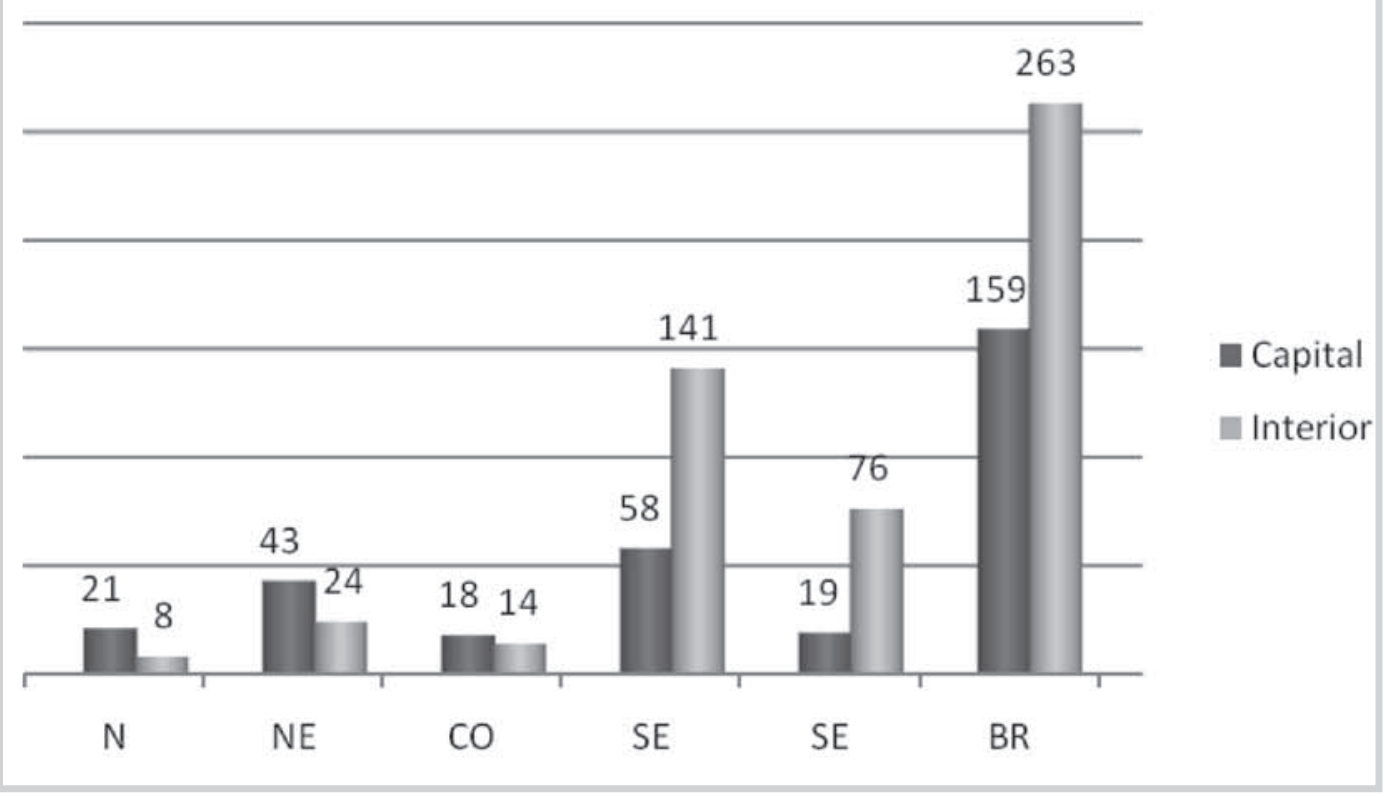

Fonte dos dados: INEP/MEC, em fev./2009

Figura 2. Cursos de Psicologia localizados nas capitais e cidades do interior do Brasil

Com o processo de regionalização da educação superior no território nacional, iniciado na década de 80 e intensificado nos anos 2000, observa-se o intenso processo de interiorização dos cursos de Psicologia por todo o País, especialmente pelas IES privadas, localizadas em cidades de médio e pequeno porte, áreas metropolitanas ou centros regionais e subcentros de desenvolvimento. Vale ressaltar que esse processo se encontra muito mais avançado no Sul (com cerca de 60 Municípios do interior que oferecem cursos de Psicologia) e no Sudeste (que conta com cerca de 100 Municípios do interior que oferecem cursos de Psicologia). Nas demais Regiões, ainda sobressai a concentração dos cursos nas capitais dos Estados, isso porque as Regiões Sul e Sudeste constituem atualmente áreas em que o setor de educação superior se encontra consolidado e com alta demanda para o interior, apesar de o processo de interiorização no Nordeste brasileiro também ter avançado, especialmente nos Estados da Bahia (dos 25 cursos existentes no Estado, 11 estão localizados no interior) e de Pernambuco (dos 13 cursos existentes no Estado, cinco estão localizados no interior).

Outro aspecto importante a ser apresentado é que o processo de interiorização dos cursos de Psicologia nas Regiões Sul, Sudeste e Nordeste brasileiro tem se encaminhado mais e mais para as cidades que apresentam certa força produtiva e competitiva no mercado, especialmente para aquelas voltadas para o setor da agricultura científica e do agronegócio, da indústria pecuária ou mesmo da indústria de base, automotiva, química e de gêneros alimentícios, ou ainda do ramo de serviços, como, por exemplo, o setor de comércio e serviços especializados, sobretudo o setor de educação ou de saúde. 
Conforme Paula (2006), Elias (2007) e Gomes (2007), as universidades brasileiras (ou demais centros ou unidades de educação superior) têm sido visualizadas como um importante agente de desenvolvimento local e regional na oferta de trabalhos mais qualificados e de transferência direta de tecnologia às empresas e ao setor de serviços para que se alavanque o crescimento de dadas regiões do País.

Nesse aspecto, entendemos ser pertinente aproximar o debate sobre as alianças entre o processo de expansão da educação superior e interiorização dos cursos de Psicologia e o movimento de reestruturação urbana por que passa o Brasil na atualidade, com o debate proposto por Mancebo (2007) sobre os efeitos do fortalecimento das relações entre o setor privado e público e a viabilização de ações de mercantilização do conhecimento. O objetivo desse exercício é justamente suscitar analisadores que problematizem o movimento da Psicologia de aumentar, cada vez mais, a sua atuação nessas áreas emergentes de desenvolvimento regional, atendendo os anseios e demandas que os psicólogos tão bem suscitam na população através da sua cultura profissional.

\section{Considerações finais}

De maneira geral, a partir do quadro de reflexões apresentado ao longo deste texto, podemos perceber que a ampliação dos horizontes da Psicologia nos últimos anos, em especial, em direção às novas territorialidades e serviços, é fruto 1) das maquinações dos psicólogos com os movimentos sociais e do envolvimento com várias bandeiras e lutas políticas, que têm se revertido no processo de descentralização das políticas sociais (saúde, saúde mental e assistência social), e em consequência, no movimento de expansão e interiorização da Psicologia como profissão, não esquecendo que, muito em breve, poderemos ter aprovado pelo poder Legislativo Federal o Projeto de Lei $n^{\circ} .60 / 2007$, que prevê a inserção de psicólogos e assistentes sociais na estrutura funcional de todas as escolas públicas municipais e 2) das alianças entre o processo de reestruturação e expansão da educação superior com o movimento de transição e reestruturação urbana do País.

Tais movimentos têm suscitado para nossa profissão e formação algumas apostas. A primeira delas é que sejam operados processos de crítica em nossa categoria que se desdobrem na ampliação e no avanço de nossas práticas, bem como no modo como atuamos, somos formados e nos constituímos psicólogos. O propósito é poder romper um certo programa normativo/ normalizador de condutas que é definidor de nossas ações profissionais, especialmente no estabelecimento de normas/padrões de comportamentos que, inclusive, funcionam como parâmetro para se regular sujeitos por certos regimes de verdade datados históricoculturalmente (Hüning \& Guareschi, 2005).

A segunda aposta é que também sejam feitas críticas quanto aos efeitos da ação de reconhecermos e considerarmos o mundo através de categorias que pretendem administrar e governar sujeitos, ou seja, através do valor de uso que tal operação traz para as nossas ações profissionais, notadamente em relação à população que solicita, reivindica e acessa nossos serviços, quando intervirmos de forma a "prevenir o indesejado, a curar o anormal e a corrigir o inadequado" (Hüning \& Guareschi, 2005, p. 117).

Operar tais críticas diz da necessidade de assumirmos uma posição que se coloque 
contrária à centralidade do modelo liberal e privatizante ainda hegemônico nos modos de atuar e de ser psicólogo no Brasil, por isso a aposta de se deflagrar na (e a partir) da profissão discursos/intervenções capazes de criar possibilidades e espaços para a produção de alteridades e de heterogênese. O objetivo aqui é o de marcarmos diferença na maneira com que constituímos nossas ferramentas de trabalho, nossos planos de intervenção e a nós próprios sujeitos nesse processo (Hüning \& Guareschi, 2005; Dimenstein, 1998), isto é, o propósito é afirmar tais princípios e postura em vez de ficarmos apenas a operar o fatídico jogo de equalizações ou "de rebatimentos e de sujeição característico da organização hegemônica do socius" em que nos encontramos (Passos \& Barros, 2009, p. $30)$.

\section{João Paulo Macedo}

Psicólogo, Mestre e Doutorando em Psicologia pela Universidade Federal do Rio Grande do Norte, e Bolsista da Coordenação de Aperfeiçoamento de Pessoal de Nível Superior/CAPES. É Professor da Universidade Federal do Piauí, Piauí - PI - Brasil.

E-mail: jpmacedo@ufpi.edu.br

\section{Magda Dimenstein}

Psicóloga, Mestre em Psicologia Clínica pela PUC/RJ e Doutora em Saúde Mental pelo Instituto de Psiquiatria da UFRJ. É Professora da Universidade Federal do Rio Grande do Norte/UFRN, vinculada ao Programa de PósGraduação em Psicologia/PPGPsi, Rio Grande do Norte - RN - Brasil.

E-mail: mgdimenstein@gmail.com

\section{Endereço para envio de correspondência:}

Universidade Federal do Piauí, Campus Ministro Reis Velloso, Departamento de Psicologia.

Av. São Sebastião, 2819 Reis Veloso, Parnaíba, PI - Brasil. CEP 64202-020

Recebido 14/10/2009, 1a Reformulação 15/10/2010, 2ª Reformulação 8/11/2010, Aprovado 23/12/2010 


\section{Referências}

Bastos, A. V. B., Gondim, S. M. G., \& Rodrigues, A. C. A. (2010). Uma categoria profissional em expansão: quantos somos e onde estamos? In A. V. B. Bastos, \& S. M. G. Gondim (Orgs.), O trabalho do psicólogo no Brasil (pp. 32-44). Porto Alegre: Artmed.

Bock, A. M. B. (2007). Psicologia e saúde: desafios às políticas públicas no Brasil. In E. M. Rosa, H. A. Novo, M. E. B. Barros, \& M I. B. Moreira (Orgs.), Psicologia e saúde: desafios às políticas públicas no Brasil (pp.17-34). Vitória, ES: EDUFES.

Böing, E. (2009). O psicólogo na atenção básica: uma incursão pelas políticas públicas de saúde brasileiras. Dissertação de mestrado, Programa de Pós-Graduação em Psicologia Universidade Federal de Santa Catarina, Florianópolis, SC.

Botomé, S. P. (1979). A quem, nós, psicólogos, servimos de fato? Psicologia, 5(1), 1-16.

Brasil. Ministério da Saúde. (2004a). Lei que dispõe sobre a proteção e os direitos das pessoas portadoras de transtornos mentais e redireciona o modelo assistencial em saúde mental. Lei n. ${ }^{\circ} 10.216$, de 6 de abril de 2001. In Ministério da Saúde (Org.), Legislação em saúde mental: 1990-2004 (pp. 17-20). Brasília, DF: Autor.

Brasil. Ministério da Saúde (2004b). Portaria que define e estabelece diretrizes para o funcionamento dos Centros de Atenção Psicossocial. Portaria $G M n^{\circ}$ 336, de 19 de fevereiro de 2002. In Ministério da Saúde (Org.), Legislação em saúde mental: 1990-2004 (pp. 125-137). Brasília, DF: Autor.

Brasil. Ministério do Desenvolvimento Social. (2004c). Política Nacional de Assistência Social. Sistema Único de Assistência Social - SUAS. Brasília, DF: Ministério do Desenvolvimento Social e Combate à Fome.

Brasil. Ministério do Desenvolvimento Social (2006). Norma operacional básica de recursos humanos do SUAS - NOB-RH SUAS. Sistema Único de Assistência Social - SUAS. Brasília,
DF: Ministério do Desenvolvimento Social e Combate à Fome.

Brasil. Presidência da República. (2007). Reestruturação e expansão das universidades federais: diretrizes gerais. Brasília, DF: Autor. Recuperado em 01 outubro 2010 de http://portal. mec.gov.br/sesu/arquivos/pdf/diretrizesreuni.pdf

Brasil. Ministério da Saúde. (2008). Portaria que cria os Núcleos de Apoio à Saúde da Família - NASF. Orientações para a implantação dos núcleos. Portaria $n^{\circ} 154$, de 24 de janeiro de 2008. Brasília, DF: Autor.

Brasil. Instituto Nacional de Estudos e Pesquisas Educacionais Anísio Teixeira (2009). Sinopse Estatística da Educação Superior - 2007. Brasília, DF: Ministério da Educação. Recuperado em 01 de outubro de 2010 de http://www.inep.gov.br/download/ superior/censo/2007/Resumo_tecnico_2007.pdf

Brasil. Ministério da Saúde (2010). Saúde mental em dados 7. Brasília, DF: Autor. Recuperado em 01 outubro 2010 de www. saude.gov.br/bvs/saudemental

Campos, R. H. F. (1983). A função social do psicólogo. Educação \& Sociedade, 5(16), 74-84

Conselho Federal de Psicologia, CFP. (1988). Quem é o psicólogo brasileiro? São Paulo: Edicon.

Conselho Federal de Psicologia, CFP. (1994). Psicólogo brasileiro: práticas emergentes e desafios para a formação. São Paulo: Casa do Psicólogo.

Dimenstein, M. (1998). O psicólogo no serviço público de saúde: impasses na formação e atuação profissionais. Estudos de Psicologia, 3(1), 53-81. Recuperado em 28 setembro 2008 de www.scielo.br/pdf/epsic/v3n1/a04v03n1.pdf

Dimenstein, M., \& Macedo, J. P. (2007). Desafios para o fortalecimento da psicologia no SUS: a produção referente 
à formação e inserção profissional. In M. J. P. Spink (Org.), A psicologia em diálogo com o SUS: prática profissional e produção acadêmica (pp. 207-234). São Paulo: Casa do Psicólogo.

Duarte, J. (2008). Regiões promissoras. Revista Ensino Superior 115(1). Recuperado em 28 setembro 2008 de http:// revistaensinosuperior.uol.com.br/textos.asp?.codigo $=12126$

Elias, D. S. (2007). Agricultura e produção de espaços urbanos não metropolitanos: notas teórico-metodológicas. In M. E. B. Sposito (Org.). Cidades médias: espaços em transição (pp. 113-138). São Paulo: Expressão Popular.

Foucault, M. (2008). O nascimento da biopolítica. Curso no Collège de France (1978 - 1979). São Paulo: Martins Fontes.

Gomes, E. T. A. (2007). Petrolina: emergências de uma cidade média, a tecnologia auxiliando na (re)produção do espaço urbano. In M. E. Sposito (Org.), Cidades médias - espaços em transição (pp.609-630). São Paulo: Expressão Popular.

Gomide, P. I. C. (1988). A formação acadêmica: onde residem suas deficiências. In Conselho Federal de Psicologia. (Org.) Quem é o psicólogo brasileiro? (pp.69-85). São Paulo: Edicon.

Hünning, S., \& Guareschi, N. M. F. (2005). Efeito Foucault: desacomodar a psicologia. In N. Guareschi, \& S. Hüning (Org.), Foucault e a Psicologia (pp. 107-127). Porto Alegre: Abrapso Sul

Instituto Brasileiro de Geografia e Estatística - IBGE. (2006). Perfil dos municípios brasileiros na Assistência Social. Rio de Janeiro: Ministério do Planejamento, Orçamento e Gestão.

Lisboa, F. S., \& Barbosa, A. J. G. Formação em psicologia no Brasil: um perfil dos cursos de graduação. Psicologia Ciência e Profissão, 29(4), 718-737. Recuperado em 01 outubro 2010 de http://pepsic.bvsalud.org/pdf/pcp/v29n4/v29n4a06.pdf

Macedo, J. P., Cabral, C., \& Dimenstein, M. (2009). A psicologia no programa de atenção integral à família. In M. Dimenstein (Org.), Produção do conhecimento, agenciamentos e implicação no fazer pesquisa em psicologia (pp. 335-350). Natal, RN: Editora da UFRN.

Mancebo, D. (1997). Formação do psicólogo: uma breve análise dos modelos de intervenção. Psicologia: Ciência e Profissão, 17(1), 20-27. Recuperado em 28 setembro 2008 dehttp:// pepsic.bvs-psi.org.br/pdf/pcp/v17n1/04.pdf

Mancebo, D. (2004). Reforma universitária: reflexões sobre a privatização e a mercantilização do conhecimento. Educação e Sociedade, 25(88), 845-867. Recuperado em 28 setembro 2008 de www.scielo.br/pdf/es/v25n88/a10v2588.pdf

Mancebo, D. (2007). Reforma da educação superior no Brasil: análises sobre a transnacionalização e privatização. Revista Diálogo Educacional, 7(21), 103-123. Recuperado em 28 setembro 2008 de http://www2.pucpr.br/reol/index.php/ DIALOGO?dd $1=1042 \&$ dd99 $=$ view

Martins, C. B. C. (2009). A reforma universitária de 1968 e a abertura para o ensino superior privado do Brasil. Educação e Sociedade, 30(106), 15-35. Recuperado em 28 setembro 2008 de http://www.scielo.br/pdf/es/v30n106/v30n106a02. pdf

Mello, S. L. (1975). Psicologia e profissão em São Paulo. São Paulo: Ática.

Neves, C. E. B., Raizer, L., \& Fachinetto, R. F. (2007). Acesso, expansão e eqüidade na educação superior: novos desafios para a política educacional brasileira. Sociologias, 9(17) 124-157. Recuperado em 28 setembro 2008 dewww.scielo. $\mathrm{br} / \mathrm{pdf} / \mathrm{soc} / \mathrm{n} 17 / \mathrm{a} 06 \mathrm{n} 17 . \mathrm{pdf}$

Oliveira, I. M. F. (2005). A psicologia no sistema de saúde pública: diagnóstico e perspectivas. Tese de doutorado, Instituto de Psicologia, Universidade de São Paulo, São Paulo.

Passos, E., \& Benevides, R. (2009). A cartografia como método de pesquisa-intervenção. In E. Passos, V. Kastrup, \& L. Escóssia (Org.), Pistas do método da cartografia: pesquisa-intervenção e produção de subjetividade (pp. 17-31). Porto Alegre: Sulina.

Paula, J. A. (2006). A cidade e a universidade. In C. A. L. Brandão (Org.), As cidades da cidade (pp. 35-54). Belo Horizonte, MG: Editora da UFMC

Rosa, P., Rosa, A., \& Xavier, I. B. (1988). Quantos e quem somos. In Conselho Federal de Psicologia. (Org), Quem é o psicólogo brasileiro? (pp.32-48). São Paulo: Edicon.

Sguissardi, V. (2008). Modelo de expansão da educação superior no Brasil: predomínio privado/mercantil e desafios para a regulação e a formação universitária. Educação e Sociedade, 29(105), 991-1022. Recuperado em 28 setembro 2008 de http://www.scielo.br/pdf/es/v29n105/v29n105a04.pdf

Sobral, F. A. (2000). A educação para a competitividade ou para a cidadania? São Paulo em Perspectiva, 14(1), 3-11. Recuperado em 28 setembro 2008dehttp://www.scielo.br/ pdf/spp/v14n1/9797.pdf

Sousa, J. V. (2006). Restrição do público e estímulo à iniciativa privada: tendência histórica no ensino superior brasileiro. In M. A. Silva, \& R. B. Silva (Orgs.), A ideia de universidade (pp. 139-178). Brasília, DF: Líber Livro.

Spink, M. J., Bernardes, J. S., Santos, L., \& Gambá, E. A. C. (2007). A inserção de psicólogos em serviços de saúde vinculados ao SUS: subsídios para entender os dilemas da prática e os desafios da formação profissional. In M. J. P.

Spink (Org.), A psicologia em diálogo com o SUS: prática profissional e produção acadêmica (pp. 53-79). São Paulo: Casa do Psicólogo.

Vargas, H. M. (2007). Interiorização do ensino superior: um debate à luz de Tocqueville. Boletim Socied., 4(1). Recuperado em 28 setembro 2008 de http://www.maxwell.lambda.ele. puc-rio.br/cgi-bin/db2www/prg_1168.d2w/input

Vasconcelos, E. M. (2009). Apresentação. Os vários significados deste livro de psicologia e de sua perspectiva de engajamento social no contexto brasileiro atual. In M. Dimenstein (Org.), Produção do conhecimento, agenciamentos e implicação no fazer pesquisa em psicologia (pp. 9-17). Natal, RN: Editora da UFRN.

Yamamoto, O. H. (2007). Políticas sociais, "terceiro setor" "compromisso social": perspectivas e limites do trabalho do psicólogo. Psicologia e Sociedade, 19(1), 30-37. Recuperado em 28 setembro 2008 de http://www.scielo.br/pdf/psoc/ v19n1/a05v19n1.pdf

Yamamoto, O. H., Souza, J. A. J., Silva, N., \& Zanelli, J. C. (2010). A formação básica, pós-graduada e complementar do psicólogo no Brasil. In A. V. B. Bastos, \& S. M. G. Gondim (Orgs.), O trabalho do psicólogo no Brasil (pp. 45-65). Porto Alegre: Artmed. 